\title{
Design and Application of High Power Full Hydraulic Drive Underground Drill
}

\author{
Zhi Liü, a , Dong Li ${ }^{2, b}$ \\ ${ }^{1}$ Xi'an Research Institute,CCTEG,Xi'an710077,China \\ ${ }^{2}$ Xi'an Research Institute,CCTEG,Xi'an710077,China \\ a email: liuzhi030191@sina.com, bemail: lidong@cctegxian.com
}

Keywords: High power; Full hydraulic drive; Drill; Design; Application

\begin{abstract}
In order to solve the problem that lower hole-making rate of gas drainage in soft outbursting coalbeds, the ZDY12000 drill is designed. The drill is composed of drilling system and dynamic system. The drilling system including spinner,gripper,feeding body and frame, dynamic system including electromotor-pump, oil tank, control console and crawler. The test and application show that ZDY12000 drill has the features of large torque output, higher hole-making rate, high drilling speed, moving convenience, which has good application prospects.
\end{abstract}

\section{Introduction}

Gas Drainage[1] is a necessary step of coal mining. The construction of drilling is the essential condition for gas Drainage. Soft outbursting coalbedsexploitation is also using the method of construct drilling in advance. For safety, beforehand deflation via the hole in layers is used in soft outbursting coalbeds exploitation. But drilling holes in layers has defects such as long operating cycle, high cost, low utilization rateeffective drilling. So there is a good way to solve the problem which is construction drilling in whole mining-coal bed.While drilling in the soft outbursting coalbeds often occur the problem that hole collapse or sticking due to the coal is soft[2] [3].

If the drilling torque output is not enough, when the accident happen, we have to finish drilling and taking out drilling pipes. So the lower hole-making rate of gas drainage in soft outbursting coalbeds is the main reason which limit the exploitation of drill in whole mining-coal bed.

ZDY12000 drill is a new equipment which adapt to operate large-diameters drainage hole in whole mining-coal bed which belongs to soft outbursting coalbeds. The advantage of equipment are large torque output, wider range of rotating speed and large diameter drilling hole. The drill can also process borehole accidents matching drilling tools. The industrial test are finished in some coal mine which belongs to HuaiNan mining bureau, the results of experiment is good, providing a new equipment and technique for solve operate large-diameters drainage hole in soft outbursting coalbeds.

\section{Experimental equipment}

\section{ZDY12000 type drill}

ZDY12000 split type of full hydraulic drive underground drill used in coal mine is special design for project used or experiment. Based on series of ZDY full hydraulic drive underground drill, combining coal seam condition and features of operate large-diameters drainage hole,technical innovation,high Power split type drill is designed. The torque output reached 12000NM,feeding ability is $250 \mathrm{kN}$.

Split type was adopted on the drill's whole Layout. Drilling system and dynamic system can be arranged according to spot situation. Electromotor-pump, oil tank and control console are installed on the crawler body. When drilling,the control console can be removed from crawler body. Compared with split ZDY series drill, the rate of translocation and relocationgreatly improved[4].The graph 1 is the physical drill photo. The table 1 is the drill's technical parameters.[5]. 
The modle of ZDY series hydraulic system has to be used on ZDY12000's famework of hydraulic system. Constant pressure variable piston pump of Parker brand from American has been used in the system, discharge capacity of main pump is $145 \mathrm{ml} / \mathrm{r}$, vice pump's discharge capacity is $28 \mathrm{ml} / \mathrm{r}$. Feeding circle, rotating circle and other assistant circles are composed framework of hydraulic system. The function of feeding circle is to driving power head forward of backward, matching other assistant circles relief feeding or vacuum feeding can be realizd.

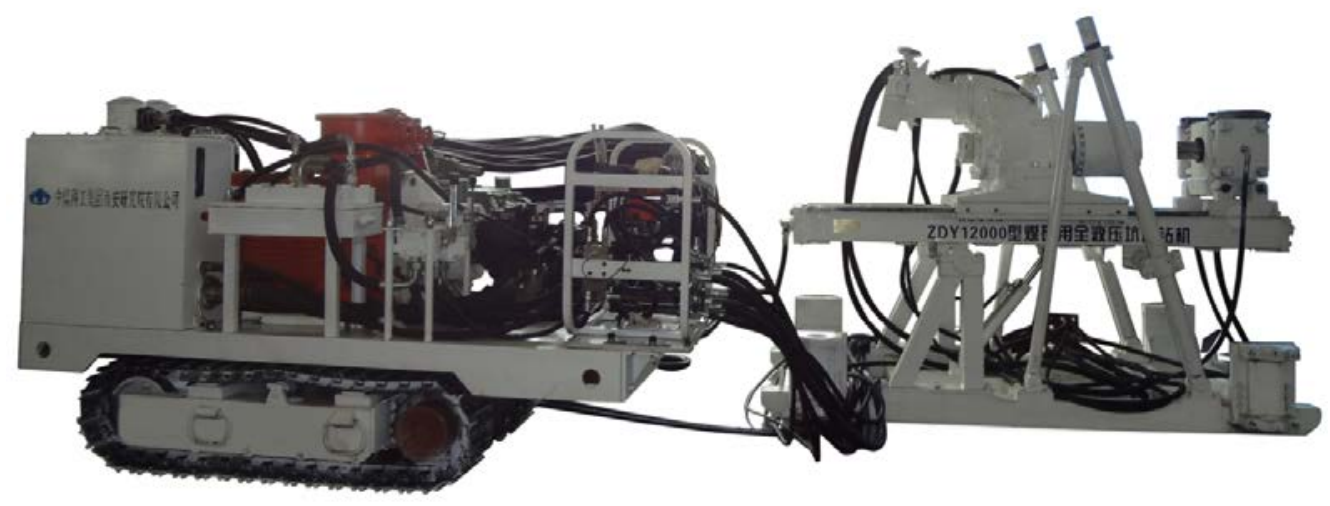

Fig.1 ZDY 12000 drill photo

The role of rotating circle is hydraulic motor driving transmission box can bring along drill pipe positive inversion. There is a main multichannel reversing valves in the hydraulic system, one piece of which is switching valve on the main circle. When pump vehicle moving, high pressure hydraulic oil produced by main pump completely entering walking motor, redundant high pressure oil entering oil tank through return pipe. High pressure oil produced by vice pump completely return to oil tank. When drilling, high pressure hydraulic oil produced by main pump entering vice switching valve in order to supplying executive mechanism motion.

Table1: The ZDY12000 drill's technical parameters.

\begin{tabular}{clcl}
\hline & Basic performance & Unit & Parameters \\
\hline \multirow{4}{*}{ Drilling } & Rated torque & $\mathrm{N} . \mathrm{m}$ & $12000 \sim 2200$ \\
system & Rated speed & $\mathrm{r} / \mathrm{min}$ & $40 \sim 150$ \\
& Main shaft angle & $\mathrm{kN}$ & 250 \\
& Ppe diameter & $\mathrm{mm}$ & $-20 \sim 20$ \\
& length $\times$ width $\times$ height & $\mathrm{mm}$ & 108 \\
& Weight & $\mathrm{kg}$ & $3000 \times 1650 \times 2100$ \\
\hline \multirow{5}{*}{ Dynamic } & Rated power of motor & $\mathrm{kw}$ & 110 \\
system & Climbing ability & $\mathrm{km} / \mathrm{h}$ & 2.0 \\
& length $\times$ width $\times$ height & $\circ$ & $20^{\circ}$ \\
& Weight & $\mathrm{mm}$ & $2900 \times 1000 \times 1665$ \\
\hline
\end{tabular}

\section{Ф108 integral helix drilling rod}

The drilling method without pressure ventilation or calm-pressing water is used in the construction of soft coal drilling. So the drill pipe with the function of spiral transportation is used on the soft coal drilling. When the drill pipe rotation, a spiral transportation belt which can bring the slack out of the hole is formed. In order to improve the drill pipe's Wear resistance, the structure of 
integral wide blade is adopted in the design of pipe. The specific parameters of drill pipe is: The diameter is $\Phi 108 \mathrm{~mm}$, Minimum inner sizes is $\Phi 50.8 \mathrm{~mm}$. Screw type drill pipe joint is NC31. The thickness of pipe body is $15 \mathrm{~mm}$, the length is $1000 \mathrm{~mm}$. The number of Spiral groove is 3,the range of Groove depth is $5 \sim 7 \mathrm{~mm}$, lead is $250 \mathrm{~mm}$.

Static torsion test on the pipe joint and body is done in order to certify the strength whether or not meet the design requirements. Torsional strength of Screw achieve $75753 \mathrm{Nm}$, torsional strength of drill body is $75213 \mathrm{Nm}$. Both of those is several times bigger than drill's rated torque, which fully meet the requirements.

\section{Ф150 scraper PDC bit}

The drill bit is composed of three wings scraper PDC bit, it suits for drilling soft coal. In order to improve the efficiency of construction mechanization, there is a very small contacting area between three wings scraper and the surface of coal, then forms bigger contacting power, combined with high rotating speed of the drill. While the success ratio of drilling process is improved by the cutting edges in the behind of three wings scraper, it can not produce much friction between the coal powder and the hole wall when working. The $\Phi 150$ scraper PDC bit is composed of the 45 steel and machined by turn-milling, then the PDC plate is welded to the drill steel bit, it has lots of advantages including high hardness, good wear resistance and high cutting efficiency. The graph 3 is the physical drill bit photo.

\section{Application}

\section{Geological condition}

The location of Zhangji coal mine which belongs to huainan mining group is in the northwest of Huainan. The seam coal of experiment is xier first seam. The average thickness of coal is 7meters. The occurrence of coal seam and strata is mainly monoclinal structure.The layer's strike $80^{\circ} \sim 95^{\circ}$, the dip $170 \sim 185^{\circ} \quad \measuredangle 8^{\circ}$. There is not large geological structure on the coal. The roof of coal is sandstone which has the phenomenon of water penetration. The elevation height of return airflow dip is $-469 \mathrm{~m} \sim-560 \mathrm{~m}$, where original gas pressure is $0.42 \mathrm{MPa}$, the original gas content is $5.18 \mathrm{~m} 3 / \mathrm{t}$.

\section{Borehole design and construction}

Nine holes in the coal seam have been done during December 16, 2014 to January 10, 2015 on the site of xier first seam. The footage is $1321 \mathrm{~m}$, among which the longest hole is $202 \mathrm{~m}$. When drill the $1 \#$ hole to the depth of $171 \mathrm{~m}$, the pressure of rotary is $12 \mathrm{MPa}$, feeding pressure is $3 \mathrm{MPa}$, drill running stationary. There is the condition to drilling the deep hole, considering there are remaining four holes and project is urgent, so stopping drilling. When drill the 6\# hole to the depth of 202m, the pressure of rotary is $16 \mathrm{MPa}$, feeding pressure is $4 \mathrm{MPa}$, drilling ability enough. Due to change of geologic conditions, when drilling the 7\#、8\#、9\#hole, water content increased in the coal, the results of residue discharge are influenced. The design longth of drill is not attachive.

\section{Conclusions}

ZDY12000 type drill is completely suit for the large diameter drilling work in soft outbursting coalbeds. Drill continues to use the traditional hydraulic system of ZDY series drill, the operation is simple and easy to use. There are nine drill holes, including six upper 140m length, the cumulative penetration was 1796 meters. The efficiency of pump truck work was greatly improved, due to the walking tracks which can drag the host moving. $\varnothing 108$ integral wide blade spiral drill pipe is suitable for long drilling construction, with its Good stiffness and high guaranteed laymen. In the subsequent design research and development, automatic adding pipe device can be installed on the drill host, which can decrease the strength of manual labor and realize the whole modern hydraulic drill. 


\section{References}

[1] De-Qiang Feng. Drill Design. Wuhan: China University of Geosciences Press,1993

[2] Zhi Liu,Dong Li,E. Development and application of ZDY series all hydraulic crawler drillers. Coal Mine Machinery. 36(3),pp90-93,2014.

[3] Ke Yao. Development and application of ZDY series all hydraulic crawler drillers. China Coal. 38(1),pp68-71,2012.

[4] Zhi Liu, Peng Fang, E. Design of hydraulic station of crawler hydraulic drilling rig. Advanced Material Research.pp.380-384,2013.

[5] Dong Fan, Xin-Sheng Yin,E. The design of ZDY1000G type all hydraulic tunnel drilling rig. Coal Geology \& Exploration.39(1).pp78-80,2011. 